\title{
ERRATUM TO BORTKIEWICZ ET AL. "MOBILE PHONE USE AND RISK FOR INTRACRANIAL TUMORS AND SALIVARY GLAND TUMORS - A META-ANALYSIS" (INT J OCCUP MED ENVIRON HEALTH 2017;30(1):27-43)
}

The original version of the article was published in the "International Journal of Occupational Medicine and Environmental Health" 2017;30(1):27-43, https://doi.org/10.13075/ijomeh.1896.00802.

1. In the Abstract the authors mistakenly input data that should appear as given correctly in bold fonts:

Results of epidemiological studies on the association between use of mobile phone and brain cancer are ambiguous, as well as the results of 5 metaanalysis studies published to date. Since the last meta-analysis (2009), new case-control studies have been published, which theoretically could affect the conclusions on this relationship. Therefore, we decided to perform a new meta-analysis. We conducted a systematic review of multiple electronic data bases for relevant publications. The inclusion criteria were: original papers, case-control studies, published till the end of March 2014, measures of association (point estimates as odds ratio and confidence interval of the effect measured), data on individual exposure. Twentytwo studies (26 846 cases, 50013 controls) were included into the meta-analysis. A significantly higher risk of an intracranial tumor (all types) was noted for the time of the mobile phone use: $\geq 10$ years (odds ratio $(\mathrm{OR})=\mathbf{1 . 4 6 , 9 5 \%}$ confidence interval $(\mathrm{CI}): 1.07-1.98)$, for the time from the first regular use of a mobile phone: $\geq 10$ years $(\mathrm{OR}=1.25,95 \% \mathrm{CI}: 1.04-1.52)$, and for the ipsilateral location $(\mathrm{OR}=1.29,95 \% \mathrm{CI}$ : $1.06-1.57)$. The results support the hypothesis that long-term use of mobile phone increases risk of intracranial tumors, especially in the case of ipsilateral exposure. Further studies are needed to confirm this relationship. Int J Occup Med Environ Health 2017;30(1):27-43

2. On page 30, paragraph 2 , line 12 the sentence should sound:

As many as 22 case-control studies on intracranial tumors and mobile phone use were included, which met following inclusion criteria (Table 1):

- papers in English,

- original, case-control peer-reviewed studies published till the end of March 2014,

- measures of association (odds ratio and confidence interval of the effect measured),

- data on individual exposure.

Corresponding author: A. Bortkiewicz, Nofer Institute of Occupational Medicine, Department of Work Physiology and Ergonomics, św. Teresy 8, 91-348 Łódź, Poland (e-mail: Alicja.Bortkiewicz@imp.lodz.pl).

This work is available in Open Access model and licensed under a Creative Commons Attribution-NonCommercial 3.0 Poland License - http://creativecommons.org/ licenses/by-nc/3.0/pl/deed.en. 